\title{
Employment retention expectations of working adults with multiple sclerosis: A multinomial logistic regression analysis
}

\author{
Jian $\mathrm{Li}^{\mathrm{a}, *}$, Richard T. Roessler ${ }^{\mathrm{b}}$, Phillip D. Rumrill $\mathrm{Jr}^{\mathrm{c}}$ and Hua $\mathrm{Li}^{\mathrm{a}}$ \\ ${ }^{a}$ Kent State University, School of Foundations, Leadership, and Administration, Kent, OH, USA \\ ${ }^{\mathrm{b}}$ Independent Rehabilitation Consultant \\ ${ }^{\mathrm{c}}$ Kent State University, Center for Disability Studies, Kent, OH, USA
}

\begin{abstract}
.
BACKGROUND: For too many cases, multiple sclerosis (MS) results in premature exit from the workforce due to both the complexity and unpredictable nature of its symptoms.

OBJECTIVE: The purpose of this investigation was to examine differential employment self-efficacy expectations on the part of employed adults with MS.

METHODS: Drawn from a larger national survey, the sample for this study $(\mathrm{N}=590)$ consisted of individuals with three types of employment expectations: continue employment for the next 2 to 5 years, decrease work responsibilities or hours in the next 2 to 5 years, and exit employment in the next 2 to 5 years.

RESULTS: Findings confirmed the utility of social cognitive theory regarding the relationship between background, physiological and affective states, performance accomplishments, and proximal contextual influences and employment expectancies. Compared to those who expected to retain their employment, those who planned to decrease work responsibilities or exit the workforce were older, more severely disabled from MS, and, in the case of those planning to decrease their job duties, less likely to have access to suitable housing.

CONCLUSION: Specific recommendations regarding intervention strategies are provided, including the need to assist minority adults with MS in securing more satisfying employment.
\end{abstract}

Keywords: Multiple sclerosis, employment expectation, self-efficacy

\section{Introduction}

Affecting more than 450,000 individuals in the United States and approximately 2.5 million in the world, multiple sclerosis (MS) is a chronic neurological illness that affects three times more women than men (Bogenschutz, Inge, Rumrill, Hinterlong, \& Seward 2016; Leslie et al., 2015). Occurring typically in the peak years of a person's career development,

\footnotetext{
*Address for correspondence: Jian Li, Kent State University, P.O. box 5190, 316 White Hall, Kent, OH 44242-0001, USA. E-mail: jli42@kent.edu.
}

MS is characterized by a wide variety of symptoms ranging from diffuse fatigue to cognitive limitations (Schiavelin et al., 2013). In too many cases, MS, like many chronic illnesses, results in premature exit from the workforce due to both the complexity and unpredictable nature of its symptoms (Antao et al., 2013; Krause, Kern, Horntrich, \& Ziemssen, 2013). Research indicates that jobless rates for adults with MS typically range from 40 to $80 \%$, with many of those individuals wishing to return to work (Julian, Vella, Vollmer, Hadjimichael, \& Mohr, 2008; Smith \& Arnett, 2005). 
Employment is important because it provides access to both material and psychological benefits. In terms of material benefits, employment enables individuals to generate the income they and their families require to meet daily living costs including the expenses of MS medications. The psychological benefits stem from the way in which the work role provides adults with a positive identity, a sense of selfesteem, social support, a means for structuring one's life, and improved quality of life (Antao et al., 2013; Moore et al., 2013; Strauser, 2014). Unemployment diminishes both these material and psychological benefits, leaving individuals and their families in a vulnerable state. For this reason, it is important to investigate the factors that result in unemployment for adults with MS and to propose rehabilitation interventions that can counter threats to job retention.

\subsection{Purpose of the study}

The purpose of this investigation was to examine factors that influence the employment expectations of adults with MS who were employed at the time of the study. For currently working adults with MS, the dependent variable, employment expectation, was coded to differentiate three groups: a) those who are currently employed and expect to remain employed for the next 2 to 5 years, b) those who are currently employed and expect to remain employed but plan to cut back on either work hours or work responsibilities in the next 2 to 5 years, and c) those who are currently employed but expect to quit working in the next 2 to 5 years. A better understanding of the factors predicting one's membership in these three groups can result in the development of early interventions that will "help these individuals compensate for their changing abilities" (Smith \& Arnett, 2005, p. 602).

Examining how these employed groups of adults with MS differ is of great value given the fact that few studies of this nature are available in the literature (Honan et al., 2012; Moore, et al., 2013). More importantly, as Smith and Arnett noted (2005), a better understanding of how these groups differ will shed light on the factors affecting their success in adapting to the employment challenges associated with MS. Findings from such a study will also suggest the types of early interventions that have the potential to reduce the high jobless rates of adults with MS. Furthermore, examining the needs of these three groups is consistent with the recommendations of several researchers in the field who have argued strongly that job retention for those currently employed is not a dichotomous outcome variable, that is, employed or unemployed (Moore et al., 2013). Rather, for those currently working, it is an outcome with three distinct classes - those working who expect to remain employed, those working who expect to cut back on hours or responsibilities to remain employed, and those working who expect to exit employment.

\subsection{Self-efficacy and the concept of employment expectation}

The key construct for this investigation is "expectation" or perceived probability of achieving a goal such as remaining employed in the face of the multiple personal and social factors associated with MS. Social cognitive theorists would label such an outlook as a "self-efficacy" expectation. In their discussions of social learning theory and social cognitive career theory, Bandura (1997) and Lent (2013) described the self-efficacy expectation as a key determinant of goal selection and behavioral enactment consistent with that goal. Lent defined self-efficacy as "people's judgments of their capabilities to organize and execute courses of action required to attain designated types of performance" (p. 118). Tansey et al. (2015) speculated that the multiple symptoms and uncertainty associated with MS are critical factors producing low self-efficacy regarding employment retention among many working adults with MS.

In this study, the self-efficacy expectation of participants refers to their expectations regarding employment in 2 to 5 years, which is influenced by both personal and environmental factors. Social cognitive career theory argues that these personal and environmental factors include the person's past performance accomplishments that may have the "greatest influence on self-efficacy," vicarious learning experiences, social persuasion and encouragement, and physiological and affective states (Lent, 2013, p. 118). The "Choice Model" of social cognitive career theory (Lent) presents a similar description of sources of self-efficacy in that self-efficacy emanates from person inputs (e.g., predispositions, physiological and affective states including disability and health status, and background characteristics), background contextual affordances (e.g., socio-economic status and quality of educational experiences), past performance accomplishments, and contextual influences proximal to choice behavior (e.g., state of the economy, work site accessibility, attitudes of employers and co-workers, and housing and transportation resources). 


\subsection{Factors affecting job retention expectations for adults with $M S$}

Past research (Bishop, Rumrill, \& Timblin, 2016; Hiele, et al., 2014) on the variables influencing the employment outcomes of adults with MS implicates many of the factors described at a more general level in social cognitive theory and social cognitive career theory. Given that fact, it stands to reason that many of those same factors would influence the employment expectations of adults with MS, although substantiation of that hypothesis is needed because it would clarify not only the similarities and differences of groups with differential employment expectations but also the high priority intervention needs of the three groups of employed adults with MS in this study. Variables of interest in such a study can be drawn from the few studies available pertaining to those with a history of retaining, exiting, or changing employment and from the broader literature on predictors of a dichotomous employment outcome (employed vs. unemployed).

\subsubsection{Factors related to retaining, exiting, or changing employment status}

Research examining employment as a three-part criterion supports the hypothesis that the sources of self-efficacy previously described (e.g., personal dispositions, disability and health status; background and proximal contextual affordances; and performance accomplishments) play a role in influencing the employment outcomes of adults with MS. It should be noted that these findings are based on the outcome of employment, not the expectation of future employment outcomes among those who are still working, which underscores the need for this research.

Moore et al. (2013) studied differences among three groups of adults with MS, those who were still employed, those who were still employed but had reduced their work hours or responsibilities, and those who were unemployed. They found that those who left or changed employment had more severe symptoms than those who retained their same positions. Comparisons between those who changed and those who left employment indicated that those who left were older and more severely disabled. Compared to the other two groups, individuals who maintained their employment tended to be younger, have more years of education, and report a shorter duration of their MS. Gender was not a significant predictor of employment status.
Smith and Arnett (2005) completed a similar study in which they examined the similarities and differences among three groups of adults with MS - those who were still working, those who had to cut back on their hours due to MS, and those who had to leave their jobs permanently due to their MS symptoms. Severity of symptoms differentiated the groups, with those who were working less severely disabled than the changed jobs group or the nonworking group. No differences among the groups appeared on age, marital status, number of symptoms, or time since diagnosis. Those who changed the nature of their jobs had more years of education than the nonworking group and occupied jobs with higher levels of occupational prestige than those in the nonworking group. The working group was not different from the nonworking group or changed employment group on either variable. The authors concluded that the option to change one's work status in adapting to MS symptoms may depend on the educational background and occupational prestige of the individuals seeking to negotiate such changes with their employers. Because of their history of higher earnings, these individuals may also have been more financially secure and able to maintain their lifestyles even with decreases in income due to fewer job responsibilities. Interestingly, these researchers found that the working group reported higher levels of depression than the changed work or nonworking groups, which they speculated may be the result of stress experienced in attempting to adapt to the unpredictability of their MS symptoms while maintaining their employment.

Factors affecting the employed vs. unemployed status. Many years of outcome research documenting the predictors of the employed versus unemployed status also underscore the importance of background characteristics and affordances (e.g., demographics), personal characteristics (e.g., dispositions and illness severity), proximal contextual influences, and performance accomplishments as important classes of predictors. Findings from this investigation are important because the influence of these predictors in many cases has not been examined among those with an "expectation" of remaining employed, changing jobs, or exiting employment.

\subsubsection{Background characteristics and affordances and personal characteristics}

Although extant findings regarding gender and ethnicity are inconsistent, older age and lower levels of education are typically related to unemployment (Julian et al., 2008; Krause et al., 2013; Simmons, 
Tribe, \& McDonald, 2010). Unemployment is consistently related to severity of MS as indicated by fatigue, decreased mobility, cognitive dysfunction, progressive disease course, and length of time disabled (Julian et al., 2008; Krause et al., 2013; Strober et al., 2012). Simmons et al. (2010) cited evidence suggesting that symptom severity was the primary reason that most adults with MS chose to leave the workforce. Evidence suggests that workers with MS who feel too stressed to work are more likely to leave employment (Simmons et al., 2010) and that rates of anxiety, depression, and suicidal ideation are elevated among adults with MS (DeLuca \& Nocentini, 2011). When controlling for other factors such as age, gender, and disease duration, self-rated health is a significant predictor of employment (Krokavcova et al., 2010).

\subsubsection{Proximal contextual affordances}

Literature reviews (e.g., Van Denand, 2006) cite findings indicating that characteristics of one's current work setting such as employer attitudes, reactions of co-workers, and favorable job accommodation policies significantly influence an individual's job retention. Factors external to the worksite itself such as availability of reliable transportation and attributes of home and family life (i.e., quality of life) affect the ability to maintain employment as well (Bishop et al., 2013; Van Denand, 2006).

\subsubsection{Performance accomplishments}

In a study of adults with MS who were employed or unemployed, Uccelli, Specchia, Battaglia, and Miller (2009) found, unsurprisingly, that those who retained employment were in situations allowing them to perform their job duties more effectively either because their MS symptoms were less involved with job duties or because they were adequately accommodated. In their research, Simmons et al. (2010, p. 931) reported a subjective aspect of performance accomplishment in that adults with MS who believed that they "were not doing a good enough job" were also more likely to exit employment. They interpreted their results as supportive of propositions in the Minnesota Theory of Work Adjustment emphasizing that acceptable job performance and long-term tenure depend upon the extent to which employees are satisfactory in their employers' estimation and satisfied with the reinforcers provided by their jobs. Sweetland, Riazi, Cano, and Playford (2007) corroborated the salience of anxiety about doing well on the job in a focus group study with people with MS. They found that one of the main themes had to do with how to improve job performance following neurological deterioration resulting from MS.

\subsection{Research questions}

To illuminate the dynamics influencing employment expectations for adults with MS, this study examined the following question: What factors predict the nature of the employment expectations held by adults with MS who are currently working? In other words, to what extent are the three groups (i.e., those who expect to remain employed over the next 2 to 5 years, those who expect to reduce their job duties or hours in the next 2 to 5 years, and those who expect to exit employment over the next 2 to 5 years) alike or different regarding variables pertaining to sources of self-efficacy such as background characteristics and affordances, personal characteristics/dispositions, proximal contextual affordances, and performance accomplishments/expectations? Given the dearth of research on employment expectations, it is difficult to hypothesize specific relationships, although one might anticipate that those having the most negative expectations about employment (unemployed 2 to 5 years from now) would have fewer personal assets, resources and affordances than either (a) those expecting to change job duties or responsibilities or (b) those expecting to remain employed over the next 2 to 5 years. Adults with MS planning to retain their jobs were expected to report the greatest level of personal assets, resources, and affordances.

\section{Methods}

\subsection{Participants}

The sample in this study was extracted from data collected in a national survey of the employment concerns of Americans with MS from nine NMSS chapters, representing 21 states and Washington, DC in the US (Rumrill et al., 2015). The sample for this study consisted of 590 participants with MS who were employed at the time of the survey, were aged between 18 and 65, and provided complete information on the employment-related measures. The sample included 482 women (82\%) and 108 men (18\%). Fifty-nine percent (59\%) of respondents described their communities as suburban, whereas $21 \%$ lived in urban areas and 20\% resided in rural settings. With an average age of $47(S D=9.85)$, 
participants in the sample were well educated (99\% were high school graduates, 59\% were college graduates). Most of the participants were Caucasians, (76\%); 9\% were African Americans; $12 \%$ were Hispanics/Latinos; and 3\% were Asians, Pacific Islanders, Native Americans, or Alaskan Natives.

Illness-related symptoms reported by the participants suggested a mixture from severe to non-severe MS conditions, as well as a wide range of physiological, sensory, and psychological effects. In descending order of frequency, the most commonly reported symptoms were fatigue (indicated by $73 \%$ of respondents), tingling (50\%), balance/coordination problems (49\%), numbness (44\%), cognitive impairment $(44 \%)$, diminished physical capacity $(41 \%)$, gait/mobility impairment $(36 \%)$, bowel or bladder dysfunction (35\%), pain (32\%), spasticity (31\%), sleep disturbance (30\%), anxiety (24\%), depression $(23 \%)$, vision problems (23\%), and sexual dysfunction (18\%). The mean number of reported MS symptoms was $6(S D=3.48)$.

\subsection{Measures}

The instrument used in this study was a 98 -item questionnaire that included fixed and open response sets. The demographic, health-related, support system, and employment-related items were developed by the research team based on a literature review and on input from several expert consultants and one working group of 13 adults with MS in the Ohio Buckeye NMSS Chapter (Rumrill et al., 2015). Variables that were considered in the present analysis were measured and coded as described in the following paragraphs.

\subsubsection{Employment expectations}

Participants with MS who were employed at the time of the survey responded to a 3 -item scale assessing their employment expectations in the next two to five years (i.e., giving up work entirely due to MS; reducing workload due to MS; changing to a less demanding type of work due to MS). The items were measured on a 5-point Likert scale ranging from very likely (1) to very unlikely (5). Based on these items, three steps were taken to create the 3-level categorical outcome variable in this study. First, the variable, giving up work entirely due to MS, was recoded into a dichotomous variable in which 0 represents the original categories of uncertain, unlikely, and very unlikely and 1 represents the original categories of likely and very likely. Next, the other two variables, reducing workload due to MS and changing to a less demanding type of work due to MS, were combined and recoded into a dichotomous variable in which 0 indicates participants who were unlikely to reduce their job duties or hours and 1 indicates those who were likely to reduce their job duties or hours. Finally, the two dichotomous variables were combined and recoded into a categorical variable that contains three types of participant employment expectations. Category 1 includes participants who expect to remain employed over the next 2 to 5 years (i.e., those who would neither give up work entirely nor reduce work demands in their job in the future); Category 2 includes participants who expect to reduce their job duties or hours in the next 2 to 5 years; and Category 3 includes participants who expect to exit employment over the next 2 to 5 years (i.e., giving up work entirely).

\subsubsection{Background characteristics}

Four demographic variables were adopted for this study to represent participants' personal backgrounds. These included gender (dichotomous; $0=$ female, $1=$ male), racial/ethnic status (dichotomous; $0=$ Caucasian, $1=$ non-Caucasian), educational attainment (dichotomous; $0=$ elementary/ secondary/some post-secondary education, $1=$ college graduate or higher), and age $(\mathrm{M}=47.14$, $S D=9.85$ ).

\subsubsection{Physiological and affective status (personal dispositions)}

Six variables representing participants' physiological and affective status were extracted for the analyses in this study. Self-reported general health status was measured on a 5-point scale ranging from 1 (poor health) to 5 (excellent health). Cognitive impairment was assessed by asking respondents to rate their current cognitive abilities on a 6-point scale, ranging from normal cognition where there is no limitation on activity or lifestyle to total cognitive disability where every day memory problems or confusion prevent doing many daily activities. Perceived symptom severity was measured on a 5-point scale ranging from no current symptoms to multiple severe symptoms significantly limiting daily functioning. Another estimate of severity of MS using the Patientdetermined Disease Steps (PDSS; Hohol, Orav, \& Weiner, 1995) measured gait/mobility impairment on a 9-point scale ranging from normal (1) to bedridden (9). The respondent's illness duration was self-reported and measured in the number of years since diagnosis. 
In addition, participants' stress coping skills were measured using the Perceived Stress Scale (Hewitt, Flett, \& Mosher, 1992), an 11-item instrument that asks respondents to report how frequently during the previous month they had encountered or dealt with stressful life events. The items were rated on a 5-point Likert scale (i.e., "1 = never", " 2 = rarely", " 3 = occasionally", " $4=$ often", " $5=$ always"). Positively stated items indicate effective coping for a particular type of stressful event (e.g., "How often have you felt that things were going your way?"). The scoring metric for negatively stated items (e.g., "How often have you felt that you were unable to control the important things in life?") was reversed to indicate effective coping and lower stress levels. The item scores were summed, and the possible range for the scale was 11-55, with higher scores indicating greater coping skills. The Cronbach Alpha coefficient for the Perceived Stress Scale within the present sample was 0.90 .

\subsubsection{Proximal contextual affordances}

Five variables representing participants' proximal contextual affordances were adopted and recoded for the analyses in this study. Current financial status, originally measured on a 3-point scale, was recoded into a dichotomous variable $(0=$ able to meet expenses, 1 = difficulty meeting expenses). Satisfaction with the transportation resources needed for daily living was measured on a 5-point scale, ranging from 1 (very dissatisfied) to 5 (very satisfied). Similarly, satisfaction with current housing accessibility was measured on a 5-point scale, ranging from 1 (very dissatisfied) to 5 (very satisfied). Participants were also asked to report on services they had received since being diagnosed with MS. A total of 18 services were included (e.g., job retention services, services from a state vocational rehabilitation program, independent living services, job training, job replacement, counseling about Social Security, etc.). A continuous variable, the number of services received, was generated from this list.

A quality of life score was also calculated using the Quality of Life Scale (Chibnall \& Tait, 1990). Respondents rated their levels of satisfaction with their functioning in seven major life areas (i.e., social life, family life, hobbies and recreational experiences, educational and intellectual development, activities of daily living, romantic experiences, expectations and hopes for the future) using a seven-point Likert scale ranging from 1 (totally unsatisfying) to 7 (completely satisfying). The possible range for the total QOL scale is 7-49, with higher scores indicating higher levels of perceived QOL. Within the present sample, the scale had high internal consistency $($ Cronbach Alpha $=0.90)$.

\subsubsection{Performance accomplishments/ expectations}

Three variables were used to represent different aspects of the subjective vocational factors related to participants' current jobs. Perceived job/personal skill match was measured on a 5-point scale ranging from 1 for complete mismatch to 5 for perfect match. Participants' perceived job satisfaction was assessed on a 5-point scale ranging from 1 (very dissatisfied) to 5 (very satisfied). The survey questionnaire also included a list of 38 employment concerns items. In responding to those items, participants indicated whether they were satisfied or dissatisfied that the concern was being addressed in their work situations. Concerns items addressed such issues as access to information on disability benefits programs, discrimination in hiring and retention practices of employers, employment protections under major legislation, the quality of rehabilitation and employment services, access to assistive technology, and support for returning to work and planning for the future. A sum score (range 0 to 38 ) was created to represent the number of employment concerns with which participants were dissatisfied, with higher values indicating greater levels of employment concern.

\subsection{Procedure}

A detailed report of the procedures that were used to develop the questionnaire and conduct the survey from which the present study sample was drawn can be found in Rumrill et al. (2015). Among the 1,932 respondents to the Rumrill et al. survey, 590 employed individuals provided complete information on the measures used in this investigation and comprised the present study sample.

\subsection{Statistical analysis}

Multinomial logistic regression analysis was performed to assess which variables were associated with the criterion variable of employment expectation. Compared to the logistic regression, which has a binary criterion variable, the multinomial logistic regression model is comprised of a set of independent binary logistic regression equations that each models the binary logit between the baseline or 
referent outcome category and one other outcome category (Hosmer, Lemeshow, \& Sturdivant, 2013). In this study, Category 1, the expectation of remaining employed over the next 2 to 5 years, was chosen as the referent outcome category. Parameters in the analysis were jointly estimated by using the maximum likelihood estimation method. Although many independent variables were collected from survey items, they were treated as continuous variables in this study to keep the model parsimonious. Therefore, one unit difference in these variables implies one increased level on the survey scale. All of the continuous variables considered in this study were grand mean centered.

A modeling procedure, the purposeful selection of covariates suggested by Hosmer et al. (2013), was adopted in the study to select a model that is not only parsimonious but also has optimal analytical power. It includes seven steps: (1) examining the univariate relationship between each independent variable and the outcome variable using a generous significance level of 0.20 to screen for candidate independent variables for the multivariable model; (2) fitting a multivariable model containing all the independent variables identified at Step 1; (3) retaining variables that were significant and removing variables that were not significant if removal of them did not change the beta coefficients of the remaining variables by more than $20 \%$; (4) adding each variable that was filtered out in step 1 back into the model one at a time and retaining the significant ones; (5) assessing the variables and changes in them more closely; (6) adding substantively meaningful interactions among variables into the model one at a time and retaining the significant ones; and (7) assessing model adequacy and checking model goodness of fit. In the modeling procedure, both the likelihood ratio $\chi^{2}$ test and the Wald test statistic were used either separately or jointly, depending on the specific purpose of each modeling step. The generalized Hosmer-Lemeshow goodness-of-fit test (Fagerland \& Hosmer, 2012) was utilized to assess the fit of the final multinomial logistic regression model. All analyses were conducted using the statistical computer package STATA 12.1 (StataCorp, 2011).

\section{Results}

\subsection{Descriptive statistics and between-group analyses}

Descriptive statistics related to characteristics of the participants for each independent variable were generated and preliminary analyses were conducted to examine how these characteristics differed in the employment expectation categories. Table 1 presents statistics related to the categorical independent variables considered by employment expectation category. Table 2 displays statistics related to the continuous independent variables given the differences in employment expectation categories. Table 3 contains the Pearson correlation coefficients among the continuous variables used in the study. The magnitude of the correlations ranges from 0.02 to 0.63 . On average, participants had been diagnosed with MS for 11.7 years $(S D=8.49)$, reported receiving few services $(M=1.40, S D=1.45)$, and indicated relatively high

Table 1

Characteristics of the study sample by categories of employment expectation in the next 2-5 years $(\mathrm{N}=590)$

\begin{tabular}{|c|c|c|c|c|c|c|c|c|}
\hline \multirow[t]{3}{*}{ Characteristics } & \multicolumn{8}{|c|}{ Employment expectation } \\
\hline & \multicolumn{2}{|c|}{$\begin{array}{l}\text { Remain } \\
\text { employed }\end{array}$} & \multicolumn{2}{|c|}{$\begin{array}{l}\text { Reduce } \\
\text { demands }\end{array}$} & \multicolumn{2}{|c|}{$\begin{array}{c}\text { Exit } \\
\text { employment }\end{array}$} & \multirow[t]{2}{*}{$\chi^{2}(d f)$} & \multirow[t]{2}{*}{$p$} \\
\hline & $\mathrm{N}$ & $\%$ & $\mathrm{~N}$ & $\%$ & $\mathrm{~N}$ & $\%$ & & \\
\hline Gender & & & & & & & $0.79(2)$ & 0.672 \\
\hline Female & 333 & 82.4 & 96 & 81.4 & 53 & 77.9 & & \\
\hline Male & 71 & 17.6 & 22 & 18.6 & 15 & 22.1 & & \\
\hline Race & & & & & & & $8.86(2)$ & $<0.05$ \\
\hline White & 322 & 79.7 & 85 & 72.0 & 44 & 64.7 & & \\
\hline Non-white & 82 & 20.3 & 33 & 28.0 & 24 & 35.3 & & \\
\hline Educational attainment & & & & & & & $9.34(2)$ & $<0.01$ \\
\hline Less than college graduate & 151 & 37.4 & 58 & 49.2 & 36 & 52.9 & & \\
\hline College graduate or above & 253 & 62.6 & 60 & 50.8 & 32 & 47.1 & & \\
\hline Current financial status & & & & & & & $25.98(2)$ & $<0.001$ \\
\hline Able to meet expenses & 298 & 73.8 & 64 & 54.2 & 34 & 50.0 & & \\
\hline Difficulty meeting expenses & 106 & 26.2 & 54 & 45.8 & 34 & 50.0 & & \\
\hline Total & 404 & 100.0 & 118 & 100.0 & 68 & 100.0 & & \\
\hline
\end{tabular}


Table 2

Characteristics of the study sample by categories of employment expectation in the next 2-5 years $(\mathrm{N}=590)$

\begin{tabular}{|c|c|c|c|c|c|}
\hline \multirow[b]{2}{*}{ Characteristics } & \multicolumn{3}{|c|}{ Employment expectation } & \multirow[b]{2}{*}{$F_{(2,587)}$} & \multirow[b]{2}{*}{$p$} \\
\hline & $\frac{\text { Remain employed }}{\mathrm{M}(\mathrm{SD})}$ & $\frac{\text { Reduce demands }}{\mathrm{M}(\mathrm{SD})}$ & $\frac{\text { Exit employment }}{\mathrm{M}(\mathrm{SD})}$ & & \\
\hline Age & $46.54(9.71)$ & $46.98(10.04)$ & $50.96(9.61)$ & 5.96 & $<0.01$ \\
\hline Health status & $3.42(0.95)$ & $2.97(0.80)$ & $2.60(0.90)$ & 29.46 & $<0.001$ \\
\hline Cognitive impairment & $2.13(1.05)$ & $2.72(1.03)$ & $2.78(1.18)$ & 21.27 & $<0.001$ \\
\hline Perceived symptom severity & $2.18(0.90)$ & $2.64(0.72)$ & $3.03(0.93)$ & 35.52 & $<0.001$ \\
\hline Illness Duration & $11.97(8.49)$ & $10.30(7.70)$ & $12.87(9.58)$ & 2.47 & 0.086 \\
\hline PDDS & $2.25(1.73)$ & $2.69(1.52)$ & $4.12(2.06)$ & 34.54 & $<0.001$ \\
\hline Coping & $38.82(7.05)$ & $35.74(6.62)$ & $34.24(6.98)$ & 18.33 & $<0.001$ \\
\hline Satisfaction with transportation accessibility & $4.03(1.26)$ & $3.82(1.30)$ & $3.85(0.97)$ & 1.61 & 0.201 \\
\hline Satisfaction with housing accessibility & $4.18(1.07)$ & $3.64(1.24)$ & $3.75(1.06)$ & 13.19 & $<0.001$ \\
\hline QOL & $36.09(8.76)$ & $31.39(8.36)$ & $28.37(8.98)$ & 30.92 & $<0.001$ \\
\hline Number of services received & $1.30(1.44)$ & $1.62(1.52)$ & $1.60(1.36)$ & 2.90 & 0.056 \\
\hline Job/personal skills match & $4.15(0.93)$ & $3.64(1.22)$ & $3.60(1.17)$ & 17.11 & $<0.001$ \\
\hline Job satisfaction & $4.05(0.99)$ & $3.44(1.14)$ & $3.41(1.26)$ & 22.00 & $<0.001$ \\
\hline Employment concerns & $9.79(11.15)$ & $12.66(11.35)$ & $13.69(12.69)$ & 5.36 & $<0.01$ \\
\hline
\end{tabular}

satisfaction with the accessibility of their housing $(M=4.03, S D=1.13)$ and transportation $(M=3.97$, $S D=1.24)$.

There were significant differences in general health status $\left(F_{(2,587)}=29.46, p<0.001\right)$, cognitive impairment $\left(F_{(2,587)}=21.27, p<0.001\right)$, symptom severity $\left(F_{(2,587)}=35.52, p<0.001\right)$, and mobility as measured by $\operatorname{PDDS}\left(F_{(2,587)}=34.54, p<0.001\right)$ among the participants with different employment expectations. Significant differences also existed in quality of life $\left(F_{(2,587)}=30.92, p<0.001\right)$, job satisfaction $\left(F_{(2,587)}=22.00, p<0.001\right)$, job/personal skill match $\left(F_{(2,587)}=17.11, p<0.001\right)$, and dissatisfaction with employment concerns $\left(F_{(2,587)}=29.46\right.$, $p<0.001)$ among participants with different employment expectations. In general, participants who expected to remain employed in the next 2 to 5 years reported higher levels of quality of life $(M=36.09$, $S D=8.76)$ than did participants with less optimistic employment expectations (Expect to reduce work demands: $M=31.39, S D=8.36$; Expect to exit workplace: $M=28.37, S D=8.98$ ). At the same time, participants who expected to remain employed in the near future reported higher job satisfaction, better job/personal skill match, and lower dissatisfaction with employment concerns than did participants with less optimistic employment expectations.

\subsection{Modeling procedure}

As a first step, a univariate multinomial logistic regression model, using the employment expectation as the outcome variable, was fitted for each independent variable. Table 4 displays the likelihood ratio $\chi^{2}$ test statistic, degrees of freedom, and $p$-value of the univariate model for each of the 18 independent variables. At the alpha level of 0.20 , only gender $(L R$ $\left.\chi^{2}=0.76, d f=2, N=590, p=0.68\right)$ and satisfaction with transportation accessibility $\left(L R \chi^{2}=3.14, d f=2\right.$, $N=590, p=0.21$ ) were not significantly related to employment expectation. Therefore, the other 16 significant independent variables in the univariate analyses were entered into a multivariable multinomial logistic regression model. The importance of independent variables was assessed by examining the $p$-value of their Wald test statistic. In the presence of other variables, 5 independent variables (i.e., age, perceived symptom severity, PDDS, satisfaction with housing accessibility, and job satisfaction) were significantly associated with employment expectation at the alpha level of 0.05 .

The removal of the 11 non-significant independent variables started one at a time, and coefficients in the model after removal were compared to those in the model before removal. If the change in magnitude was less than $20 \%$, the removed independent variable would be excluded permanently; if not, the removed variable would be added back into the model. We were not able to exclude any of the 11 non-significant variables from the analysis because dropping any of them would lead to a coefficient change greater than $20 \%$. This process indicated that these variables, even though not significant in a zero-order sense, were still important in terms of their contributions to the needed effect adjustment of other variables that remained in the model (Hosmer et al., 2013). This makes sense because several variables, particularly the health-related variables, were moderately 


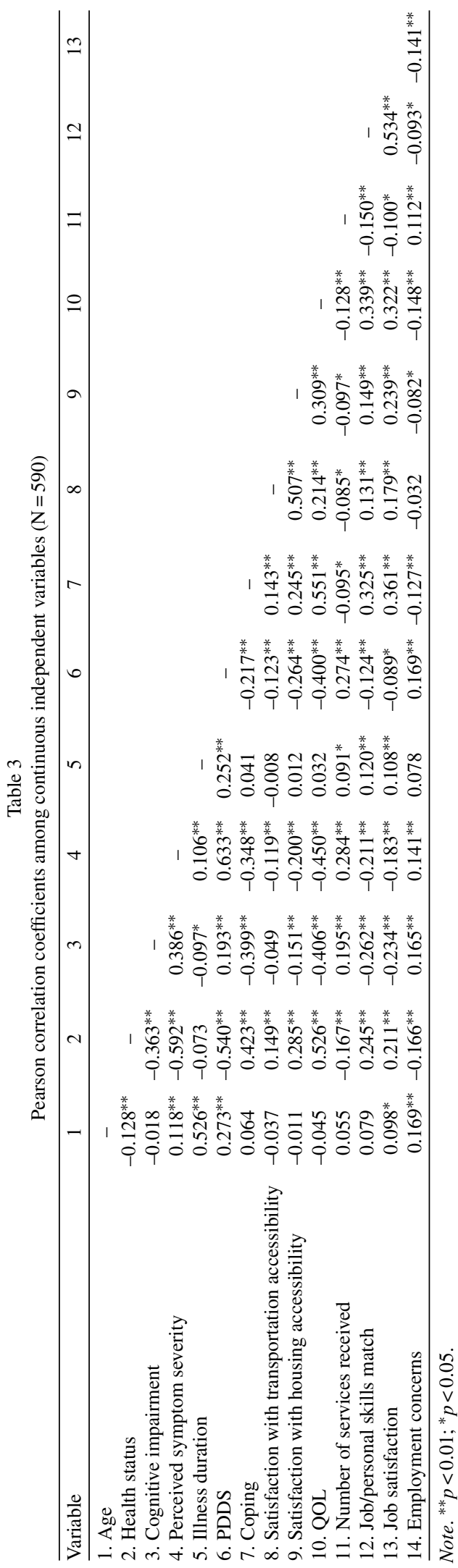

correlated (as seen in Table 3) and each of them captured some aspects of the disease. As a result, these variables were put back into the model.

Next, the variables that were set aside in the first step (i.e., gender and satisfaction with transportation accessibility) were added back into the model one at a time. Both of them remained non-significant in their association with employment expectation; thus, they were permanently excluded from the analysis. The final main effect model contained 16 independent variables: race, educational attainment, age, health status, cognitive impairment, perceived symptom severity, illness duration, PDDS, coping, current financial status, satisfaction with housing accessibility, QOL, number of services received, job/personal skills match, job satisfaction, and dissatisfaction with employment concerns.

Based on previous research, four meaningful interaction terms were identified and included in the main effect model one at a time. These interaction terms were (1) dissatisfaction with employment concerns vs. job/personal skills match, (2) perceived symptom severity vs. QOL, (3) cognitive impairment vs. PDDS, and (4) race vs. job satisfaction. A likelihood ratio $\chi^{2}$ test statistic was evaluated for each interaction. Using the alpha level of 0.05 , only the interaction between race and job satisfaction was retained in the model, which concluded the modeling procedure and rendered us with a final model.

\subsection{Multinomial logistic regression analysis}

The omnibus test for the final model was significant $\left(L R \chi^{2}=164.90, d f=34, N=590, p<0.001\right)$, indicating that the independent variables were collectively and significantly associated with the employment expectations of people with MS. The pseudo $R^{2}$ 's in logistic regression models are not very meaningful if they are not used for model comparison on the same sample data for the same outcome variable. However, they are reported here for the interest of readers. The Cragg and Ulher's pseudo $R^{2}(1970)$ was 0.30 and the McFadden's pseudo $R^{2}(1974)$ was 0.17 in this study. The model fit was assessed by using the generalized Hosmer-Lemeshow goodness-of-fit test. The test results $\left(\chi^{2}=20.47, d f=16, N=590\right.$, $p=0.20)$ indicated that the model fit the data well.

Table 5 displays the estimated multinomial logistic regression coefficients that predict employment expectations in log-odds units for each independent variable included in the final model; the standard 
Table 4

Results of fitting univariate models with three categories of employment expectation as the outcome

\begin{tabular}{lccr}
\hline Independent variable & $\begin{array}{c}\text { Likelihood } \\
\text { Ratio Test }\end{array}$ & df & $p$ \\
\hline Gender & 0.76 & 2 & 0.682 \\
Race & 8.43 & 2 & 0.015 \\
Educational attainment & 9.27 & 2 & 0.01 \\
Age & 12.41 & 2 & 0.002 \\
Health status & 57.75 & 2 & $<0.001$ \\
Cognitive impairment & 39.57 & 2 & $<0.001$ \\
Perceived symptom severity & 65.93 & 2 & $<0.001$ \\
Illness Duration & 5.10 & 2 & 0.078 \\
PDDS & 54.37 & 2 & $<0.001$ \\
Coping & 35.21 & 2 & $<0.001$ \\
Current financial status & 25.31 & 2 & $<0.001$ \\
Satisfaction with transportation accessibility & 3.14 & 2 & 0.208 \\
Satisfaction with housing accessibility & 24.28 & 2 & $<0.001$ \\
QOL & 56.49 & 2 & $<0.001$ \\
Number of services received & 5.59 & 2 & 0.061 \\
Job/personal skills match & 31.68 & 2 & $<0.001$ \\
Job satisfaction & 39.98 & 2 & $<0.001$ \\
Employment concerns & 10.34 & 2 & 0.006 \\
\hline
\end{tabular}

error associated with the coefficient estimates; the corresponding Wald test statistic and its $p$-value; the odds ratio (OR) coefficients; and the $95 \%$ confidence interval for the odds ratio. The odds ratio provides information related to the change in the odds of being in the non-referent categories of employment expectation that would be associated with a one-unit change in a given independent variable. Employment expectation in the next 2 to 5 years among people with MS was significantly associated with participants' perceived symptom severity, satisfaction with housing accessibility, race, age, PDDS and the interaction between race and job satisfaction.

To be specific, holding all the other variables in the model constant and using the expectation to remain employed as the reference category, the odds of expecting to reduce work demands in the next 2 to 5 years for employed people with MS would increase by a factor of 1.5 for every one level increase in their perceived symptom severity $\left(\operatorname{Wald}_{(1)}=2.25, p<0.05\right)$, and decrease by a factor of 0.8 for every one level increase in self-reported satisfaction with housing accessibility $\left(\right.$ Wald $_{(1)}=-2.35$, $p<0.05$ ). The odds of expecting to exit the work force for employed people with MS would increase by a factor of 1.07 for every one unit increase in their age $\left(\operatorname{Wald}_{(1)}=3.31, p<0.01\right)$, by a factor of 1.6 for every one level increase in their perceived symptom severity $\left(\operatorname{Wald}_{(1)}=2.13, p<0.05\right)$, and by a factor of 1.3 for every one level increase in their mobility impairment as measured by the PDDS $\left(\operatorname{Wald}_{(1)}=2.67, p<0.01\right)$.
The interaction term between race and job satisfaction was a significant explanatory variable for the $\log$ odds of expecting to exit work in the next 2 to 5 years for employed people with MS $\left(\right.$ Wald $_{(1)}=-0.77$, $p<0.01$ ). It was a marginally significant explanatory variable for the log odds of expecting to reduce work demands in the next 2 to 5 years $\left(\right.$ Wald $_{(1)}=-0.39$, $p=0.096$ ). To facilitate interpretation, the effects of the relationship between race and job satisfaction on the odds of expecting to reduce work demands and the odds of expecting to exit work are graphed in Fig. 1. The trend pattern is readily observable in the two plots. Using the plot on the right as an example and holding all the other variables in the model constant, the relationship between job satisfaction and the odds of expecting to exit the workplace in the next 2 to 5 years among employed people with MS is different in different racial/ethnic groups (i.e., Caucasian vs. non-Caucasian). For Caucasians, the odds stayed almost the same when job satisfaction increased. For non-Caucasians, the odds of expecting to exit the workplace in the next 2 to 5 years was the highest when their job satisfaction was at the lowest level and it decreased sharply when their job satisfaction increased. From another perspective, the difference between the two racial groups of employed people with MS in the odds of expecting to exit the workplace in the next 2 to 5 years was the largest when job satisfaction was at its lowest level. The odds of expecting to exit the workplace was much higher for people with MS who were not Caucasians. As job 
Table 5

Characteristics associated with employment expectation in the final multinomial logistic regression model

\begin{tabular}{|c|c|c|c|c|c|c|c|}
\hline Variable & Coef. & Std. & Wald & $p$ & OR & \multicolumn{2}{|c|}{ OR $95 \% \mathrm{CI}$} \\
\hline \multicolumn{8}{|c|}{ Expectation of reducing demands relative to expectation of remaining employment } \\
\hline Race & -0.07 & 0.30 & -0.25 & 0.805 & 0.93 & 0.51 & 1.67 \\
\hline Educational attainment & -0.14 & 0.24 & -0.61 & 0.540 & 0.87 & 0.54 & 1.37 \\
\hline Age & 0.03 & 0.01 & 1.77 & 0.077 & 1.03 & 1.00 & 1.05 \\
\hline Health status & -0.11 & 0.17 & -0.66 & 0.507 & 0.89 & 0.64 & 1.24 \\
\hline Cognitive impairment & 0.18 & 0.12 & 1.55 & 0.121 & 1.20 & 0.95 & 1.52 \\
\hline Perceived symptom severity & 0.42 & 0.19 & 2.25 & $0.025^{*}$ & 1.52 & 1.05 & 2.19 \\
\hline Illness Duration & -0.03 & 0.02 & -1.95 & 0.051 & 0.97 & 0.94 & 1.00 \\
\hline PDDS & -0.12 & 0.09 & -1.30 & 0.194 & 0.89 & 0.74 & 1.06 \\
\hline Coping & 0.00 & 0.02 & 0.23 & 0.817 & 1.00 & 0.97 & 1.05 \\
\hline Current financial status & 0.19 & 0.27 & 0.70 & 0.485 & 1.21 & 0.71 & 2.04 \\
\hline Satisfaction with housing accessibility & -0.24 & 0.10 & -2.35 & $0.019^{*}$ & 0.78 & 0.64 & 0.96 \\
\hline QOL & -0.01 & 0.02 & -0.68 & 0.498 & 0.99 & 0.96 & 1.02 \\
\hline Number of services received & 0.01 & 0.08 & 0.17 & 0.862 & 1.01 & 0.87 & 1.19 \\
\hline Job/personal skills match & -0.16 & 0.13 & -1.24 & 0.214 & 0.85 & 0.66 & 1.10 \\
\hline Job satisfaction & -0.14 & 0.14 & -0.95 & 0.340 & 0.87 & 0.66 & 1.15 \\
\hline Employment concerns & 0.01 & 0.01 & 1.07 & 0.286 & 1.01 & 0.99 & 1.03 \\
\hline Race*Job satisfaction & -0.39 & 0.24 & -1.66 & 0.096 & 0.68 & 0.43 & 1.07 \\
\hline Intercept & -1.35 & 0.21 & -6.38 & 0.000 & 0.26 & 0.17 & 0.39 \\
\hline \multicolumn{8}{|c|}{ Expectation of exiting workplace relative to expectation of remaining employment } \\
\hline Race & 0.27 & 0.40 & 0.67 & 0.503 & 1.31 & 0.60 & 2.88 \\
\hline Educational attainment & -0.24 & 0.31 & -0.77 & 0.444 & 0.79 & 0.43 & 1.44 \\
\hline Age & 0.07 & 0.02 & 3.31 & $0.001^{*}$ & 1.07 & 1.03 & 1.11 \\
\hline Health status & -0.17 & 0.23 & -0.72 & 0.469 & 0.85 & 0.54 & 1.33 \\
\hline Cognitive impairment & 0.18 & 0.15 & 1.24 & 0.216 & 1.20 & 0.90 & 1.61 \\
\hline Perceived symptom severity & 0.49 & 0.23 & 2.13 & $0.033^{*}$ & 1.64 & 1.04 & 2.58 \\
\hline Illness Duration & -0.04 & 0.02 & -1.83 & 0.067 & 0.96 & 0.92 & 1.00 \\
\hline PDDS & 0.28 & 0.11 & 2.67 & $0.008^{*}$ & 1.32 & 1.08 & 1.63 \\
\hline Coping & -0.02 & 0.03 & -0.79 & 0.431 & 0.98 & 0.93 & 1.03 \\
\hline Current financial status & 0.02 & 0.35 & 0.06 & 0.953 & 1.02 & 0.51 & 2.04 \\
\hline Satisfaction with housing accessibility & 0.03 & 0.15 & 0.20 & 0.843 & 1.03 & 0.77 & 1.38 \\
\hline QOL & -0.01 & 0.02 & -0.63 & 0.530 & 0.99 & 0.94 & 1.03 \\
\hline Number of services received & -0.10 & 0.10 & -0.96 & 0.336 & 0.91 & 0.75 & 1.10 \\
\hline Job/personal skills match & -0.15 & 0.16 & -0.92 & 0.355 & 0.86 & 0.63 & 1.18 \\
\hline Job satisfaction & 0.00 & 0.19 & -0.01 & 0.995 & 1.00 & 0.69 & 1.44 \\
\hline Employment concerns & 0.01 & 0.01 & 0.79 & 0.427 & 1.01 & 0.99 & 1.04 \\
\hline Race*Job satisfaction & -0.77 & 0.28 & -2.71 & $0.007^{*}$ & 0.46 & 0.27 & 0.81 \\
\hline Intercept & -2.38 & 0.30 & -7.82 & 0.000 & 0.09 & 0.05 & 0.17 \\
\hline
\end{tabular}

Note. ${ }^{*} p<0.05$.

satisfaction increased, the difference in odds between the two racial/ethnic groups became smaller. The group difference almost disappeared when job satisfaction was at its highest level.

\section{Discussion}

Consistent with social cognitive theory (Lent, 2013) and research on MS (Chiu et al., 2013), findings from this study indicate that multiple factors play a role in predicting the type of employment self-efficacy expectations held by employees with MS whether it be optimistic (i.e., expecting to be employed for the next 2 to 5 years) or pessimistic (i.e., expecting to reduce job obligations or exit the workforce in the next 2 to 5 years). Specifically, 16 of the 18 variables in the social cognitive performance model were retained in the final model, all of which are consistent with results reported in the literature (Moore et al., 2013; Bishop, Rumrill, \& Timblin, 2016). Health, job, housing, and age variables and the interaction of race and job satisfaction were important considerations in understanding employment expectations. Older individuals with more severe MS symptoms, particularly mobility impairments, inaccessible housing, and negative job conditions were more likely to have pessimistic expectations regarding their employment outlook. In any triage approach to rehabilitation services, particularly the provision of third party on-the-job accommodation services (Sweetland, Riazi, Cano, \& Playford, 2007), 

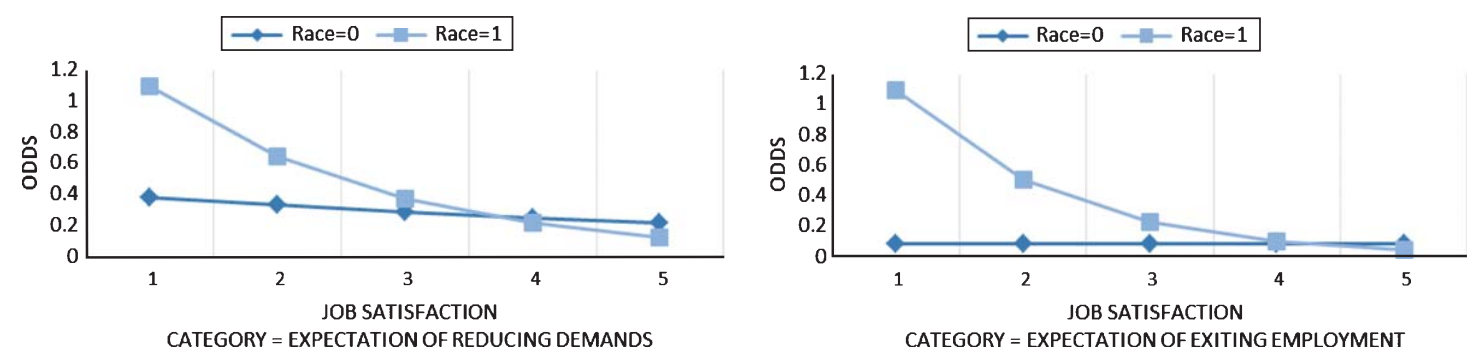

Fig. 1. Interaction effects between race and job satisfaction.

employees with MS fitting this profile should receive early attention and adequate resources.

The failure of gender to stay in the model is consistent with findings of previous studies in which gender was not a predictor of employment status (Chiu et al., 2013; Frain et al., 2015; Moore et al., 2013; Roessler, Fitzgerald, Rumrill, \& Koch, 2001; Strober, Chiaravalloti, Moore, \& DeLuca, 2014). This indicates encouraging equivalence in the experiences of men and women with MS in the world of work. The failure of transportation accessibility to stay in the model may result from the 2 to 5-year time frame in the employment expectation question. Possibly participants were not thinking ahead to practical matters such as accessible and reliable transportation as their symptoms become more severe.

The fact that the results are consistent with relationships in the performance model is important both theoretically and practically. As proposed theoretically, variables in each of the 4 categories background characteristics, physiological and affective states, proximal contextual factors, and performance accomplishments - represent precursors to both expectations and goal-directed behavior. From a practical perspective, these variables have important relationships to the diagnostic and service planning efforts of rehabilitation counselors (Roessler, Rubin, \& Rumrill, 2017). To encourage employment retention among adults with MS, counselors must determine how these variables have influenced the lives of their clients with MS as well as the types of interventions needed to address such influence whether it be in planning initial or follow-up services. Even though closure is the immediate goal of rehabilitation counseling, employment professionals should not overlook the need to monitor over time negative changes in these factors (i.e., follow-up services) given their potential to cause employees with MS to develop a "turnover intention" (Pack, Turner, Roessler, \& Robertson, 2007). The need for monitoring of this nature is reflected in the large number of adults with MS who leave the workforce prematurely (Moore et al., 2013), which may occur for many of the participants in this study.

The results also underscore the multiplicity of services needed to promote positive employment expectations, although the number of services received was not statistically significant in the final model. Unfortunately, participants in this study, regardless of their employment expectation, reported receiving very few services, specifically none to three, related to their vocational and independent living rehabilitation needs. This situation is problematic given that research indicates that services from rehabilitation counselors in terms of job placement assistance, on-the-job supports, maintenance supports, and assistive technology services are associated with employment (Chiu et al., 2013).

Many explanations exist for this small number of interventions in the lives of employed adults with MS. For some, the explanation may simply be lack of knowledge of the types of services available through programs such as the State-Federal vocational rehabilitation agency, Social Security Administration benefits planning and assistance programs, and the National Multiple Sclerosis Society. For others, lack of involvement in service programs may stem from fear of disclosure to their employers due to the stigma and subsequent employment discrimination associated with chronic illnesses such as MS (Vickers, 2012). Given their fear of the results of disclosure, some employees with MS may avoid requesting services or accommodations, viewing it as tantamount to self-identification as a person with a chronic health condition. The scope of this problem is indicated by the fact that approximately one-third of employees with MS report encountering discrimination on the job (Roessler et al., 2011), with the most frequent allegation filed with the Equal Employment Opportunity Commission (EEOC) being unlawful discharge (Neath, Roessler, Rumrill, \& McMahon, 2007). Again, rehabilitation counselors should not 
only inform adults with MS of the services available to support their community and vocational functioning but also provide them with preventive strategies for dealing with discrimination such as knowing how to (a) request on-the-job accommodations (Roessler \& Rumrill, 2015), (b) seek protection under the law (Americans with Disabilities Act Amendments Act; Rubin, Roessler, \& Rumrill, 2016), and (c) enlist the aid of the EEOC in cases of employment discrimination (Neath et al., 2007; Sweetland et al., 2007). Fortunately, research indicates that rehabilitation counselors are keenly aware of the need to provide their employed clients with MS with "career stabilization" (e.g., evaluating assistive technology needs, providing job accommodations and work supports) rather than "career exploration" services (Tansey et al., 2015).

In direct comparisons with those who expected to remain employed for the next 2 to 5 years, adults with MS who predicted that they would reduce their work obligations or exit the workforce in the same time frame were influenced differentially by the variables in the performance model. Those expecting to reduce their job responsibilities perceived themselves as more severely disabled from their MS symptoms and as more constrained by lack of accessible housing. Adults with MS expecting to exit the workforce in 2 to 5 years presented a profile consistent with the literature pertaining to predictors of employment and unemployment (Honarmand, Akbar, Kou, \& Feinstein, 2011; Moore et al., 2013; Schiavelin et al., 2013; Smith \& Arnett, 2005). They were older and perceived that they were affected more severely by their MS symptoms, particularly as those symptoms affected their mobility, which is consistent with Chiu's et al. (2015) findings that unemployed adults with MS had the highest level of incapacity in comparisons with employed adults with MS (full-time or part-time). Possibly those with more pessimistic employment outlooks in this study believed that they required more intensive help coping with the uncertainty of MS as a progressive condition, feelings of declining competency and inability to contribute, and the challenges of requesting job accommodations and countering on-the-job discrimination (Bogenschutz, Rumrill, Inge, \& Hinterlong, 2016; Sweetland et al., 2007).

Although consistent with prior findings regarding needed rehabilitation interventions, these findings also underscore the importance of a proximal contextual factor, access to suitable housing, as part of any long-term placement plan. To increase the probability of job retention, these plans should address not only maintenance of health status and accommodation of employment limitations due to MS symptoms but also provision of appropriate housing. Research indicates that level of home functioning, availability of needed accessibility features and the funds to secure them, and perceived need for assistance in the home are significant predictors of employment (Bishop et al., 2013).

Finally, results underscore the importance of the interaction of racial/ethnic status and job satisfaction. As compared to Caucasians with MS, minority individuals with MS were more likely to consider reducing their commitment to or exiting jobs that provide little personal satisfaction. One possible explanation for this finding is that minority adults, in the face of coping with worsening MS symptoms and stressors encountered in employment, appear less likely to perceive any other compelling reasons to stay employed in jobs in which they experience little or no job satisfaction. In comparisons with non-minority employees, they may be less likely to (a) receive the support services needed to retain employment, (b) earn wages that exceed what is available through benefit programs (Chiu et al., 2013), (c) have access to employee benefits such as health insurance, or (d) have an employed spouse earning an adequate income. Conversely, Caucasian adults with MS may have greater access to other compensating factors or supports in less satisfying jobs that enable them to retain more optimistic expectancies about future employment.

\subsection{Limitations}

The present study had several limitations that should be kept in mind when interpreting results. These included the complete reliance on self-report data, the low response rate (26\%) in the original survey from which this study's data were drawn, the use of a single-item measure of the employment expectation criterion, possible bidirectionality in the relationship between employment expectations and several of the employment-related predictors (e.g., job satisfaction, employment concerns), and the restricted range of responses that resulted from the categorical coding of most independent and dependent variables. Also, the criterion variable is a proxy representing the anticipation of an event rather than the occurrence of that event. Finally, future employment expectation research should utilize larger samples, and readers should note that 
findings from this study of Americans with MS may not generalize to people with MS in other countries.

\section{Conclusion}

The findings of this study provide supportive evidence for the performance model in social cognitive theory, which specifies that background, physiological and affective processes, proximal contextual variables, and performance accomplishments influence self-efficacy expectations and subsequent goal-directed behavior. Consequently, rehabilitation professionals have a concrete depiction of the factors influencing how their clients cope with the symptoms of MS in their efforts to retain employment. This model is useful for both diagnostic and treatment purposes. The findings also remind counselors of the importance of issues beyond vocational considerations such as accessible housing, which should be attended to in service planning and monitoring.

To deter adults with MS from prematurely leaving employment, counselors can draw on these findings to identify individuals at high risk. In this study, older individuals with MS with more severe mobility limitations and inadequate housing were more likely candidates to develop a "turnover intention." Providing them with high priority services addressing sources of information on MS and employment, appropriate techniques for requesting an accommodation, and preferred means for dealing with on-the-job discrimination represent high priority interventions.

Recommendations for serving those with the greatest need extend to individuals from racial/ethnic minority groups who hold jobs providing little personal satisfaction. Results suggested that they had fewer reasons to continue in employment in such jobs than non-minority adults with MS. The reasons for this finding are beyond the scope of this study but worthy of further inquiry. At the most general level, it appears that minority adults with MS have few compensating reasons to maintain less satisfying employment.

\section{Acknowledgments}

This research was funded through a Health Care Delivery and Policy Research grant from the National Multiple Sclerosis Society, New York, NY. The authors wish to thank the National Multiple
Sclerosis Society, its participating chapters, and the study participants for their support and assistance with this research.

\section{Conflict of interest}

None to report.

\section{References}

Antao, L., Shaw, L., Ollson, K., Reen, K., To, F., Bossers, A., \& Cooper, L. (2013). Chronic pain in episodic illness and its influence in work occupations. Work: A Journal of Prevention, Assessment, and Rehabilitation, 44, 11-36.

Bandura, A. (1997). Self-efficacy: The exercise of control. New York, NY: Freeman.

Bishop, M., Roessler, R., Rumrill, P., Sheppard-Jones, K., Frain, M., Waletich, B., \& Umeasiegbu, B. (2013). The relationship between housing accessibility variables and employment status among adults with multiple sclerosis. Journal of Rehabilitation, 79(4), 4-14.

Bishop, M., Rumrill, P., \& Timblin, R. (2016). Medical, psychosocial, and vocational aspects of multiple sclerosis: Implications for rehabilitation professionals. Journal of Rehabilitation, (82)(2), 6-13.

Bogenschutz, M., Inge, K., Rumrill, P., Hinterlong, P., \& Seward, H. E. (2016). Barriers and facilitators of employment among Americans with multiple sclerosis: Results of a qualitative study. Journal of Rehabilitation, 82(2), 59-69.

Chibnall, J., \& Tait, R. (1990). The Quality of Life Scale: A preliminary study with chronic pain patients. Psychology and Health, 4, 283-292.

Chiu, C. Y., Chan, F., Bishop, M., deSilva Cardoso, E. \& O’Neill, J. (2013). State vocational rehabilitation services and employment in multiple sclerosis. Multiple Sclerosis Journal, 19, 1655-1664.

Cragg, J. G., \& Ulher, R. S. (1970). The demand for automobiles. The Canadian Journal of Economics, 3, 386-406.

DeLuca, J., \& Nocentini, U. (2011). Neuropsychological, medical, and rehabilitative management of persons with multiple sclerosis. Neurorehabilitation, 29, 197-219.

Fagerland, M. W., \& Hosmer, D. W. (2012). A generalized Hosmer-Lemeshow goodness-of-fit test for multinomial logistic regression models. The Stata Journal, 12(3), 447-453.

Frain, M., Bishop, M., Rumrill, P., Chan, F., Tansey, T., Strauser, D., \& Chiu, C. Y. (2015). Multiple sclerosis and employment: A research review based on the International Classification of Function. Rehabilitation Research, Policy, and Education, 29, 153-164.

Hewitt, P., Flett, G., \& Mosher, S. (1992). The Perceived Stress Scale: Factor structure and relation to depression symptoms in a psychiatric sample. Journal of Psychopathology and Behavioral Assessment, 14, 247-257.

Hiele, K., Middelkopp, H., Ruimschold, R., Kamminga, N., \& Visser, L. (2014). A pilot study on factors involved with work participation in the early stages of multiple sclerosis. PLoS One 9(8), e105673. 
Hohol, M., Orav, E., \& Weiner, H. (1995). Disease steps in multiple sclerosis: A simple approach to evaluate disease progression. Neurology, 42, 251-255.

Honan, C., Brown, R., Hine, D., Vowels, L., Wollin, J., Simmons, R., \& Pollard, J. (2012). The multiple sclerosis work difficulties questionnaire. Multiple Sclerosis Journal, 18, 871-880.

Honarmand, K., Akbar, N., Kou, N., \& Feinstein, A. (2011). Predicting employment status in multiple sclerosis patients: The utility of the MS functional composite. Journal of Neurology, 258, 244-249.

Hosmer, D. W., Lemeshow, S., \& Sturdivant, R. X. (2013). Applied logistic regression (3rd ed.). New York, NY: Wiley.

Julian, L., Vella, L., Vollmer, T., Hadjimichael, O., \& Mohr, D. (2008). Employment in multiple sclerosis: Exiting and reentering the work force. Journal of Neurology, 255, 1354-1360.

Krause, I., Kern, S., Horntrich, A., \& Ziemssen, T. (2013). Employment status in multiple sclerosis: Impact of disease-specific and non-disease specific factors. Multiple Sclerosis Journal, 19, 1792-1799.

Krokavcova, M., Nagyova, I., Van Dijk, J., Rosenberger, J., Gavelova, M., Middel, B., Szilasiova, J., Gdovinova, Z., \& Groothoff, J. (2010). Self-rated health and employment status in patients with multiple sclerosis. Disability and Rehabilitation, 32, 1742-1748.

Lent, R. (2013). Social cognitive career theory. In S. Brown \& R. Lent (Eds.), Career development and counseling: Putting theory and research to work. (2nd ed., pp. 115-146). Hoboken, NJ: John Wiley.

Leslie, M., Kinyanjui, B., Bishop, M., Rumrill, P., \& Roessler, R. (2015). Patterns in workplace accommodations for people with multiple sclerosis to overcome cognitive and other diseaserelated limitations. NeuroRehabilitation, 37, 425-436.

McFadden, D. (1974). Conditional logit analysis of qualitative choice behavior. In P. Zarembka (Ed.), Frontiers in Econometrics (pp. 105-142). New York: Academic Press.

Moore, P., Harding, K., Clarkson, H., Pickersgill, T., Wardle, M., \& Robertson, N. (2013). Demographics and clinical factors associated with changes in employment in multiple sclerosis. Multiple Sclerosis Journal, 19, 1647-1654.

Neath, J., Roessler, R., Rumrill, P., McMahon, B. (2007). Patterns in perceived employment discrimination for adults with multiple sclerosis. Work, 29, 255-274.

Pack, T., Turner, R., Roessler, R., \& Robertson, J. (2007). Prediction of turnover intentions among employed adults with multiple sclerosis. Journal of Rehabilitation, 73(3), 26-35.

Roessler, R., Fitzgerald, S., Rumrill, P., \& Koch, L. (2001) Determinants of employment status among people with multiple sclerosis. Rehabilitation Counseling Bulletin, 45, 31-39.

Roessler, R., Hennessey, M., Neath, J., Rumrill, P., \& Nissen, S. (2011). The employment discrimination experiences of adults with multiple sclerosis. Journal of Rehabilitation, 77(1), 20-30.

Roessler, R., Rubin, S., \& Rumrill, P. (2017). Case management and rehabilitation counseling. Austin, TX: PRO-ED.

Roessler, R., \& Rumrill, P. (2015). Enhancing productivity on your job: The "win-win" approach to reasonable accommodations. New York: National Multiple Sclerosis Society.
Rubin, S., Roessler, R., \& Rumrill, P. (2016). Foundations of the vocational rehabilitation process. Austin, TX: PRO-ED.

Rumrill, P., Roessler, R., Li, J., Daly, K., \& Leslie, M. (2015). The employment concerns of Americans with multiple sclerosis: Perspectives from a national sample. Work: A Journal of Prevention, Assessment, and Rehabilitation, 52(4), 735-748.

Schiavelin, S., Leonardi, M., Giovannetti, A., Antozzi, C., Brambilla, L., Confalonieri, P., Mantegazza, R., \& Raggi, A. (2013). Factors related to difficulties with employment in patients with multiple sclerosis: A review of 2001-2011 literature. International Journal of Rehabilitation Research, 36(2), 105-111.

Simmons, R., Tribe, K., \& McDonald, E. (2010). Living with multiple sclerosis: Longitudinal changes in employment and the importance of symptom management. Journal of Neurology, 257, 926-936.

Smith, M., \& Arnett, P. (2005). Factors related to employment status changes in individuals with multiple sclerosis. Multiple Sclerosis, 11, 602-609.

StataCorp. (2011). Stata Software: Release 12. College Station, TX: StataCorp LP.

Strauser, D. (2014). Career development, employment, and disability in rehabilitation. New York, NY: Springer.

Strober, L., Christodoulou, C., Benedict, R., Westervelt, H., Melville, P., Scherl, W., Weinstock Grittman, B., Rizvi. S., Goodman, A., \& Krupp, L. (2012). Unemployment in multiple sclerosis: The contribution of personality and disease. Multiple Sclerosis Journal, 18, 647-653.

Strober, L., Chiaravalloti, N., Moore, N., \& DeLuca, J. (2014). Unemployment in multiple sclerosis: Utility of the MS Functional Composite and cognitive testing. Multiple Sclerosis Journal, 20, 112-115.

Sweetland, J., Riazi, A., Cano, S., \& Playford, E. (2007). Vocational rehabilitation services for people with multiple sclerosis: What patients want from clinicians and employers. Multiple Sclerosis, 13, 1183-1189.

Tansey, T., Strauser, D., Frain, M., Bishop, M., Chiu, C., Kaya, C., \& Chan, F. (2015). Differential vocational rehabilitation service patterns related to the job retention and job seeking needs of individuals with multiple sclerosis. Rehabilitation Research, Policy, and Education, 29, 109-121.

Uccelli, M., Specchia, C., Battaglia, M., \& Miller, D. (2009). Factors that influence the employment status of people with multiple sclerosis: A multi-national study. Journal of Neurology, 256, 1989-1996.

VanDenand, T. (2006). Employment needs of people with multiple sclerosis: A review of current literature and application to occupational therapy practice. Occupational Therapy in Health Care, 20(1), 61-77.

Vickers, M. (2012). Antinarratives to inform health care research: Exploring workplace illness disclosure for people with multiple sclerosis (MS). Journal of Health and Human Services Administration, 35, 170-206. 